\title{
'That is a place where I would want to go': investigating digital nature to enhance social wellbeing among older adults
}

\author{
Josca van Houwelingen-Snippe ${ }^{1 *}$ (D), Somaya Ben Allouch ${ }^{2,3}$ (D) and Thomas J. L. van Rompay ${ }^{1}$ \\ ${ }^{1}$ Department of Communication Sciences, Faculty of Behavioural, Management and Social Sciences, \\ University of Twente, Enschede, The Netherlands, ${ }^{2}$ Research Group Digital Life, Amsterdam University of \\ Applied Sciences, Amsterdam, The Netherlands and ${ }^{3}$ Informatics Institute, University of Amsterdam, \\ Amsterdam, The Netherlands \\ ${ }^{*}$ Corresponding author. Email: j.vanhouwelingen-snippe@utwente.nl
}

(Accepted 3 November 2021)

\begin{abstract}
Feelings of disconnectedness and social isolation among older adults are increasingly recognised as important challenges of our times. Interestingly, nature interaction can stimulate social connectedness and enhance perceived social support, indicating that nature can contribute to social wellbeing. However, nature may not always be around or accessible for older adults. In such cases, digital nature could provide an alternative means for enjoying nature's benefits. To identify limitations and restrictions that older adults experience with respect to nature interaction, and to explore preferences with respect to digital nature and their potential for influencing social wellbeing, two studies are reported: a qualitative study comprising focus groups with Dutch care centre residents $(\mathrm{N}=26)$ and a subsequent quantitative study $(\mathrm{N}=200)$ testing effects of digital landscapes on social wellbeing measures. Findings from the focus groups indicate that opportunities for nature interaction and preferences for digital nature vary with mobility restrictions, whereas findings from the quantitative study testify to the potential of digital nature for enhancing social wellbeing and related emotions. These findings extend research on how (digital) nature interventions can contribute to the social wellbeing of older adults and pinpoint essential nature characteristics important for doing so.
\end{abstract}

Keywords: social wellbeing; mobility; loss of independence; nature interactions; digital nature; social aspirations; loneliness

\section{Introduction}

Social wellbeing among older adults is increasingly recognised as a serious public health concern, in particular when it comes to social isolation and loneliness (Liu and Rook, 2013; Cacioppo et al., 2017; Courtin and Knapp, 2017). To illustrate, loneliness not only has a negative impact on mental wellbeing, it can also have

(C) The Author(s), 2022. Published by Cambridge University Press. This is an Open Access article, distributed under the terms of the Creative Commons Attribution licence (http://creativecommons.org/licenses/by/4.0/), which permits unrestricted re-use, distribution and reproduction, provided the original article is properly cited. 
detrimental effects on physical health (Sorkin et al., 2002; Hawkley and Cacioppo, 2007; Smith and Victor, 2019). Interestingly, research shows that living close to nature can reduce feelings of loneliness and enhance feelings of social support (Maas et al., 2009; Bergefurt et al., 2019; Buecker et al., 2020). Likewise, when people feel related to nature, they experience a greater sense of connectedness to other people and to the world at large (Zelenski and Nisbet, 2014). These findings align with a growing body of literature stressing the beneficial effects of nature interaction on general wellbeing, and social and mental dimensions of wellbeing in particular (Kaplan and Kaplan, 1989; Bratman et al., 2019).

However, for older adults, nature may not always be around or access to nature may be limited or troublesome due to mobility restrictions. In those situations, the question becomes how to bring nature inside in order to allow older adults to enjoy nature's charms. Interestingly, several studies show that indirect contact with nature, such as exposure to pictures and videos, can have effects comparable to real nature interaction (Beukeboom et al., 2012; Keniger et al., 2013; van Rompay and Jol, 2016). For instance, even brief exposures to nature videos or awe-evoking nature images during a day can boost people's mood and emotions (Joye and Bolderdijk, 2014; Browning et al., 2020).

New technologies, such as Virtual Reality (VR) and Augmented Reality (AR), hold particular promise as they allow for the creation of immersive nature scenes accentuating nature characteristics important for social wellbeing. For instance, in a recent study, animated nature projections (depicting fascinating, wide-open landscapes) implemented in a Dutch care centre enhanced social engagement among residents (Ludden et al., 2019). Hence, when interaction with real nature is not feasible due to old age and related mobility restrictions or safety concerns, virtual nature could serve as an alternative to interaction with outdoor nature (Battisto et al., 2018; White et al., 2018; Browning et al., 2020).

However, as of yet, there are no guidelines for the design of digital nature environments, including characteristics such as level of realism, type of nature, tree density, etc. Also, when it comes to the effects of specific nature characteristics on (social) wellbeing measures, research is largely silent. However, recent studies point to the importance of interacting with vast (rather than dense) settings for promoting pro-social behaviour, and related emotions such as awe and wonder (e.g. Piff et al., 2015; van Houwelingen-Snippe et al., 2020a). As for older adults, research findings indicate that logistic landscape characteristics such as wellmaintained paths and facilities to sit down become increasingly important with old age as they provide more opportunities for social interaction, comfort and a sense of safety (Wen et al., 2018).

To explore limitations and restrictions that older adults experience in interacting with nature, and to test the effects of digital nature on wellbeing measures, two studies are reported. Study 1 describes the results of focus group sessions conducted within Dutch care centres. Emphasis during these sessions was on (a) restrictions and limitations that older adults experience when interacting with nature and (b) their preferences for digital nature scenes. In Study 2, digital nature environments were designed (a) to test their potential on (social) wellbeing-related outcome measures and (b) to test whether nature animations varying in terms of spaciousness (based on previous research testifying to the importance of this variable for social 
wellbeing; van Houwelingen-Snippe et al., 2020a) and nature type (i.e. forest or park scenes) would influence the effects of digital nature on outcome measures. To this end, an online survey study was conducted in which respondents $(\mathrm{N}=$ 200 , aged 55 years old and above) watched immersive nature scenes optimised based on findings of the focus groups.

Before elaborating on the details of the present study, we will first discuss the key notions involved.

\section{Theoretical framework}

\section{Social wellbeing among older adults}

Loneliness among older adults is a key determinant of social wellbeing and poses a serious public health concern (Liu and Rook, 2013; Cacioppo et al., 2017; Courtin and Knapp, 2017) which does not only affect social and mental wellbeing but also undermines physical health, including greater risk of cardiovascular disease (Sorkin et al., 2002) and accelerated physiological decline (Hawkley and Cacioppo, 2007). Various reviews have been undertaken focusing on loneliness among older adults (Courtin and Knapp, 2017; Landeiro et al., 2017) and possible interventions for preventing or reducing feelings of loneliness (Dickens et al., 2011; Fakoya et al., 2020). Factors predicting loneliness among older adults are widowhood, older age, poor mental or physical health, and being new in a community (de Koning et al., 2017).

These findings align with perceptions of older adults with health issues who often perceive the world around them getting smaller, not in the least because of reduced opportunities to engage with the outside world and to maintain their social network (ten Bruggencate et al., 2019). Although bringing nature inside obviously does not enhance frequency of social interactions, it can inspire feelings of connectedness with the 'world at large' as also indicated by a recent study conducted during the present COVID-19 pandemic: people felt more connected to their community after (rather than before) watching a four-minute digital nature video (van Houwelingen-Snippe et al., 2020b). In sum, bringing nature inside might be a fruitful strategy to improve social wellbeing among frail older adults by enhancing feelings of connectedness and related emotions.

\section{Nature and social wellbeing}

Nature is an under-recognised healer, a recent report of the Institute for European Environmental Policy says (Mutafoglu et al., 2017). This claim is supported by a growing body of research showing that exposure to nature is not just pleasant or aesthetically pleasing, but positively influences a wide variety of measures related to wellbeing, including attention restoration (Kaplan and Kaplan, 1989; Keniger et al., 2013), mental health (Bratman et al., 2019), recovery after medical procedures (Ulrich, 1984), and creativity and inspiration (van Rompay and Jol, 2016).

A limited number of studies also hint at the potential of nature to enhance social wellbeing (Maas et al., 2009; Cartwright et al., 2018). For instance, findings suggest that people living nearby nature generally experience higher levels of social support 
and experience less loneliness (Maas et al., 2009). In line with these findings, loneliness has been shown to correlate with the perceived distance to urban green spaces such as parks and recreational areas (Cartwright et al., 2018; Bergefurt et al., 2019). These findings suggest that having nature around can increase social wellbeing and perceptions of connectedness (Weinstein et al., 2009).

\section{Older adults and nature interaction}

Contact with nature and the close proximity of nature play a particularly important role in older adults' everyday life (Finlay et al., 2015). By consequence, a relatively large body of research focuses on preferences for nature among older adults (Detweiler et al., 2012; Kabisch et al., 2017; Wen et al., 2018). For instance, older adults who engage in recreational activities in green spaces particularly value naturalness, aesthetics and variety within the scene (Wen et al., 2018). Additionally, findings indicate that older adults evaluate green settings in terms of accessibility, mobility and safety considerations, explaining the perceived importance of well-maintained paths and facilities for social contact in a safe environment (Wen et al., 2018).

In line with the above, therapeutic gardens and horticultural therapy have also been pointed out as particularly suited for older adults, in general (Milligan et al., 2004; Detweiler et al., 2012), and to people living with dementia, in particular (Hernandez, 2007; Murphy et al., 2010). For instance, providing care and services in green surroundings have been shown to enhance feelings of connectedness with nature, stimulate social interactions and add a sense of meaning to everyday life (de Bruin et al., 2021). However, such care practices are obviously not available at all times, and for many adults with mobility restrictions, they are an exception rather than the norm.

\section{Digital nature as complementary strategy}

When it comes to bringing nature inside, various types of nature representations have been used across a wide range of studies (for a review, see Keniger et al., 2013), varying from images, to posters, to videos (Beukeboom et al., 2012; van Rompay and Jol, 2016). Overall, findings show that such indirect encounters with nature can at least to some extent confer the same benefits as interactions with real nature (Keniger et al., 2013).

As discussed, VR and AR offer particular promise as they allow for enhanced immersion (when compared to watching static images or videos; Chirico and Gaggioli, 2019), and they can be integrated with various (physical) activities in different settings (Bruun-Pedersen et al., 2014, 2016; Ludden et al., 2019). For instance, inhabitants of a retirement home, who performed a biking exercise while watching an augmented natural environment, reported having had the feeling of being outside and experienced curiosity to explore the environment (Bruun-Pedersen et al., 2014). In line with these findings, several review articles show that virtual nature can be a good alternative when real-life nature interaction is not feasible or available (Battisto et al., 2018; White et al., 2018). However, although the potential of immersive technologies for simulating nature is generally acknowledged, research pinpointing essential nature characteristics for stimulating social wellbeing is very limited. 


\section{Nature characteristics and social wellbeing}

When it comes to preferences of older adults and social wellbeing, it is an open question which nature types are most beneficial. Further underscoring this lack of understanding, a recent study found no difference in wellbeing outcomes between simulated park-like grassland and forest-like woodland (Choe et al., 2020). Likewise, in a study assessing the mental health of local residents as a function of the presence and amount of public green spaces (Wood et al., 2017), a positive correlation was not only found for parks or other green spaces with an explicit nature focus (i.e. green settings with the specific aim of providing contact with nature), but also for green spaces aimed at recreation or practising sports.

When zooming in on social wellbeing, tended nature scenes might be particularly suitable for social interactions as they are readily associated with social presence and hence with safety and security (cf. Staats and Hartig, 2004), as also indicated by the importance of well-maintained infrastructure and facilities to older adults (Wen et al., 2018).

Additionally, recent studies in emotion research indicate that interactions with vast and wide-open settings inspire awe, defined as a sense of being in the presence of something greater than oneself (Keltner and Haidt, 2003; Shiota et al., 2007; Cohen et al., 2010). Awe is accompanied by decreased self-focus and increased connectedness with other people, the community and the world at large (Keltner and Haidt, 2003). Of particular relevance to the present context, a laboratory study with university students showed that wide-open and spacious (rather than dense) digital landscapes enhanced social aspirations and triggered awe (van HouwelingenSnippe et al., 2020a). However, so far, research has not addressed preferences and social benefits of spacious landscapes among older adults.

\section{Research aims}

The aim of Study 1 (consisting of focus group sessions conducted within Dutch nursing homes) was to explore limitations that older adults experience in interacting with nature, and to study (related) preferences for digital nature environments (Aim 1). Study 2 presents the results of a quantitative study aimed at testing the effects of enhanced digital nature scenes (varying in terms of spaciousness and type of nature) on measures related to social wellbeing, including social aspirations, awe, fascination and sense of presence (Aim 2).

\section{Study 1: Focus groups \\ Method}

The study received approval from the ethical committee.

\section{Participants}

Five focus groups were conducted (pre-COVID-19) within two care centres in the eastern part of the Netherlands. Groups consisted of four to nine older adults, between 69 and 92 years old (mean $=83$ ), with different care needs. Care professionals recruited participants within the care centres who were mentally and physically able to participate in group discussions. Focus groups either comprised 
residents of the care centres involved or older adults living individually (but nonetheless receiving care or services provided by the care centre; see Appendix 1 for more information on demographics and focus group composition). Prior to participation, informed consent forms were signed by the participants. The focus group sessions took approximately 60-90 minutes (including informal introductions with coffee and tea).

\section{Focus group set-up}

The (semi-structured) focus group sessions consisted of two different parts. During the first part, introductory questions were asked to form a picture of how often and in what (social) contexts participants experienced nature. In the second part, different digital nature scenes (for examples, see Figure 1) were shown, and participants were asked for their opinion on style and content. The digital nature scenes were created using an advanced game development platform (Unity; Gaia Package $)^{1}$ and varied in terms of spaciousness and type of nature.

\section{Methodology}

Common themes and concepts were identified by carefully analysing all transcripts. The coding process used a mixed-method approach, such that some of our themes were based on prior knowledge from literature (deductive approach), while other themes emerged directly from the participants' narratives (inductive approach) (Ryan and Bernard, 2003). The authors performed several rounds of coding to compare new codes to previously assigned codes, to make sure the identified themes remained valid and to derive the final set of themes.

\section{Data analysis}

The coding process was performed using Atlas.ti 8 software and consisted of three stages, derived from Corbin and Strauss (1990): (a) open coding, in which the themes emerging from the transcripts were coded in vivo using constant comparison; (b) axial coding, where themes were connected and combined into categories; and (c) selective coding, in which a storyline was uncovered based on the recurring themes.

\section{Results Part 1: Context}

The data of the first part were structured using four themes, grouped into the two categories 'nature interaction' and 'physical limitations'.

\section{Category 'nature interaction'}

At the start of each focus group, participants were asked whether they considered themselves a 'nature person' (conversation starter) which triggered meaningful discussions and revealed an overall desire for more interaction with nature and a perceived lack of contact with nature in their daily lives (elaborated on below).

Desire for nature interaction. A theme that was mentioned numerous times during the focus groups was the expressed desire for nature interaction or a perceived lack thereof. Generally, participants expressed a personal connection with nature and most participants identified themselves as a 'nature person'. However, often, 

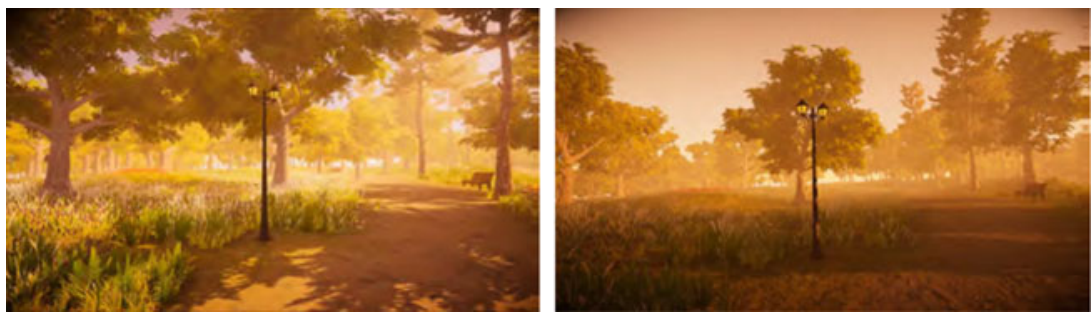

Figure 1. Screen shots of digital nature animations presented during the focus group sessions (left: dense tended nature; right: spacious tended nature).

participants mentioned that they were not able to go into nature as often as they used to or less frequently as they would like:

So, I am a nature person but at the moment that no longer works. $\left(1.1^{2}\right)$

I found nature very beautiful, but I hardly ever come there anymore, only on a few occasions. (5.1)

I love nature very much, but I have hardly ever been there in recent years. Because ... Yes, everything [gestures, to hands and electric wheelchair]. But I did that a lot, with deer and with the birds. And yes, the little hedgehogs. All those things and stuff. (5.1)

Other responses more specifically reveal a sense of sadness about not being able to go out and enjoy nature:

Yes, I just love nature and I miss it. I also live on the third floor and I often miss

[it] sometimes, but I have a nice view though. But uh, I just love nature. (3.4)

The following excerpt likewise illustrates the perceived lack of nature interaction and resulting negative emotions (i.e. frustration and indignation) for participants who cannot go out independently:

Interviewer (I): Do you ever get picked up to go out into nature together?

1.2: $\quad$ No, never!

I: $\quad$ Never? Do you have that desire?

1.2: $\quad$ Yes, walking.

Social activities in nature. Within the context of our study, we were especially interested in what types of social situations participants associate with nature. The following excerpts reveal a connection between spending time with family and going out in nature:

I: Do you sometimes go to the forest or the park with a friend or family member? 
2.8: Walking with my son.

I: And will your son come to pick you up to do that? Or do you meet together?

2.8: No, he always picks me up, because it is much too far to walk. We have always done this.

Very coincidentally, last week when my daughter came, we planned to go to the city, she said 'well, it is such nice weather, we will do something else'. And then we went to the Arboretum [regional nature park] and yes, my husband was able to come too. And it is so beautiful there. We enjoyed it. (3.3)

These quotes highlight the enjoyment participants derive from nature visits but at the same time illustrate that the initiative to go outside often rests with the informal care-giver, as also illustrated by the following excerpt:

I: $\quad$ Are there people to take you outside?

1.4: Two are there, my granddaughters. And I really appreciate that.

I: And when your granddaughter picks you up, do you ask her if she can come?

1.4: No, she says 'I will pick you up this afternoon'.

Next to social nature interactions with family members, other participants referred to possibilities offered by the care centre (i.e. 'home care'; care professionals that attend to the care needs of older adults living individually) or associations that allow older adults to engage in physical activities:

I: Who do you go to the forest with then?

2.7: With the home care.

I: And the fishing you just talked about, are you still doing that now?

4.1: Yes, every Monday. But now it is no longer possible, it is getting too cold. We are under the supervision of a fishing association. So, when a fish takes the hook, the rod is pulled behind us by one of them. But I really enjoy it, I like it.

\section{Category 'physical limitations'}

The participants in our focus groups discussed several types of physical limitations as a consequence of ageing. The most frequently voiced concerns were the loss of mobility and the related dependency on others.

Mobility. Lack of mobility (i.e. not being able to go out due to physical limitations) was often seen as a restricting factor for the participants in our study, as illustrated by the following excerpt:

I: And how is that for you, do you ever go out into nature together? 
4.1: Well not lately, of course, because you live here internally. But I used to go out a lot. Also going away for a long weekend and then with the children ... Out and about; up the trails, down the lanes!

I: $\quad$ But not so often now?

4.1: No, no, no.

I: What is holding you back then?

4.1: That I am old, physically it is no longer possible. Look, I'm in a wheelchair, it is not possible, it doesn't work anymore.

For other participants, electronic wheelchairs turned out to be an important means for going outside and regaining a sense of autonomy and independency:

4.3: I am certainly a nature person and if it no longer works with the bicycle, then I go with the electronic wheelchair. I spend a lot of time outside.

4.3: I love to go out into nature, but then alone.

I: Have you always done this alone?

4.3: Ever since I am alone, I do indeed prefer doing it alone. Because my electronic wheelchair takes me everywhere. And it is not always possible to ask friends or acquaintances like 'hi, I want to go out, are you coming?' Because then you have to ask someone on a bike to come along with the electronic wheelchair and then you have to ride one after the other. And then I think: it is much more practical if I just go alone.

Having access to an electronic wheelchair seems to give back some of the mobility or autonomy one might have lost due to (age-related) physical limitations. Participant 4.3 expresses in the above excerpt that her electronic wheelchair takes her everywhere, she therefore does not seem to experience any loss of mobility, although she acknowledges that going outside together has become more complicated by the use of an electronic wheelchair.

Loss of independence and dependence on others. Due to physical limitations, many of the participants in our study expressed some sort of loss of independence and autonomy, which turned out to be quite an emotional theme throughout the focus groups, as illustrated by the following excerpts:

Doing the groceries ... I can't go that far anymore. It is difficult though. You have always been independent and then you think about it, don't you? You are dependent on someone else and that is difficult. I find that very difficult to deal with. (1.2)

Because you can do so much for so long and then everything is gone all at once. You can't do anything anymore. (1.3) 
I: Do you ever go out into nature together?

1.1: Only a little. We can walk less than two metres without both of us lying on the ground.

I: But do you sometimes get picked up to go with a family member?

1.2: No, no, no!

1.1: No because they all have to work and stuff.

1.2: Family don't do that, and neighbours neither. Nobody does that.

I: Well, that is a pity.

1.1: Yes, that is not nice.

1.2: Yes, and you would like to go for a walk. Even if only for a short time.

However, there were also participants who do not feel dependent on others (access to an electronic wheelchair was frequently mentioned here as well):

I: Do you enjoy doing that [going into nature] together?

1.5: No, no. If you can do it alone, you can do as you please. You don't have to ask anyone 'do you go here or there?'

I: So, you just enjoy doing that alone?

1.5: Yes, it's nice to go alone.

These findings hint at an important distinction between older adults who are fully dependent on other people for going out in nature (with negative emotions including frustration and sadness as a result) and those who can manage to go out in nature by themselves (oftentimes supported by an electronic wheelchair).

\section{Results Part 2: Digital nature animations}

In the second part of the focus groups, digital nature animations were presented, and participants were asked for their opinion.

\section{Reactions towards nature scenes}

First reactions to the tended nature scenes were somewhat varied. On the one hand, there were very positive reactions of participants who expressed the desire to be actually present in the scene presented:

I: [Dense tended nature scene] What is your first impression?

1.1: I find this quite beautiful ... I would want to go for a walk there.

I: You would want to go for a walk there?

1.1: Yes, lovely. Smelling nature. It all smells so wonderful. 
[Spacious tended nature scene] I just think this is really beautiful. The trees and everything. I just really see myself walking on such a path. (3.4)

On the other hand, there were participants who were much more critical, in particular participants who did not suffer from mobility restrictions and were less dependent on others. Common themes of criticism were realism (including depicted movement and the colours of the digital nature animations):

[Dense tended nature] I don't think this is beautiful ... The colours are absolutely unnatural. And well, the trees are not finely lined ... At least, I don't like this recording. (5.3)

[Dense tended nature] But this has nothing to do with reality. The colours too. (3.2)

[Dense tended nature] However, these bushes are wiggling weirdly ... As one piece, then I think, guys that is not right (everyone laughs). It should only be the upper part of a plant that moves a bit, but not the entire bush that wiggles from side to side, then there really has to be quite a storm coming. (5.3)

Somewhat surprisingly, there were no comments or remarks pertaining to the difference between dense and spacious scenes within this category (for an example, see Figure 1), suggesting that this variable was less important to older adults, regardless of mobility constraints.

As for the wild nature scenes, in particular those participants who were rather negative about the tended nature scenes (i.e. those participants who could go out by themselves) seemed to be more positive about the wild nature scenes:

Yes, this is a real forest ... I love the roughness. (3.4)

I find this more natural. (2.8)

However, other participants expressed explicit negative emotions or associations with this scene:

Very sad ... I don't like this at all. (3.1)

Has there been a fire? No, I do not think the nature there is beautiful. (1.5)

Yes, this is a desolate scene. (4.1)

Overall, a preference was observed for the tended nature scenes. However, findings also suggest a relationship between mobility restrictions, on the one hand, and nature preferences, on the other: participants who experienced a loss of mobility seemed to prefer the tended nature scenes while this was not the case for participants who experienced high levels of autonomy and independence. 


\section{Summary Study 1}

The aim of the focus groups was to explore limitations older adults experience in interacting with nature, and to study (related) preferences for digital nature environments (Aim 1). Findings suggest that mobility restrictions (and related levels of autonomy and independence) play a crucial role in whether older adults experience a lack of nature interaction. Especially for older adults who experience a lack of nature interaction, digital nature could provide a meaningful addition to everyday life. Furthermore, findings suggest that for these older adults in particular, tended nature scenes are preferred over wild scenes. This finding aligns with literature stressing the importance of accessibility and well-maintained paths (Wen et al., 2018). However, with respect to the distinction between dense and more spacious nature scenes, no clear preferences emerged.

In terms of digital nature characteristics, realism might well be an important factor influencing acceptance, especially among relatively independent older adults. Several participants commented on the use of too bright and artificial colours. This feedback served as input for the development of the digital nature scenes used in Study 2.

Furthermore, findings of Study 1 did not provide insights into the effects of digital nature on subjective wellbeing measures. Arguably, effects of nature scenes are largely implicit and hence do not surface in focus group sessions where participants consciously reflect on differences in nature scenes. In line with this notion, research indicated that awareness of natural surroundings and their effects is no precondition for the restorative effect of green elements (e.g. trees in urban settings) to take place (Lin et al., 2014). Hence, in addition to incorporating preferences of older adults in a next iteration of nature scenes, Study 2 aimed to test the effects of nature type (i.e. tended nature versus wild nature) and spaciousness of digital nature scenes on social wellbeing measures specifically.

\section{Study 2: Online survey \\ Research aim}

In the second study, we aimed to test effects of the enhanced digital nature scenes (varying in terms of spaciousness and type of nature) on measures related to social wellbeing, including social aspirations, awe, fascination and sense of presence (Aim 2).

\section{Method}

The study received approval from the ethical committee.

\section{Experimental design}

The study employed a 2 (spaciousness: dense versus spacious) $\times 2$ (nature type: wild versus tended nature) mixed design with spaciousness as within-subject variable and nature type as between-subjects variable. In other words, participants were assigned to one of the 'nature-type' conditions and watched two videos varying in spaciousness in randomised order. 


\section{Stimulus development}

Incorporating the feedback of Study 1 (e.g. enhancing realism of the scenes), four different animated nature scenes (dense tended nature, spacious tended nature, dense wild nature, spacious wild nature) were developed using the game development platform (Unity; Gaia Package). ${ }^{3}$ As for the nature-type manipulation, the animations display either a tended scene (i.e. a park-like scene with benches, lampposts and a well-defined path) or a wild nature scene, without any of these objects; see Figure 2). This latter manipulation was based on focus group results hinting at the importance of social affordances (e.g. benches) and the importance of a safe setting (e.g. with lampposts).

As for the spaciousness manipulation, the spacious condition presents a wideopen view with a limited number of trees whereas in the dense condition, view is restricted by a large number of trees populating the scene. All scenes display a stationary viewpoint and depict subtle movements of vegetation, corresponding shadows and clouds. All conditions were accompanied by the same soundtrack with bird sounds.

\section{Respondents}

Respondents $(\mathrm{N}=200)$ were recruited online using Amazon's Mechanical Turk, i.e. a large-scale online tool to recruit respondents meeting specific requirements in exchange for a fair pay. Inclusion criteria were age (55 years or older) and location (northern European countries, Canada and the United States of America (USA)).

\section{Procedure}

Prior to participation, respondents filled out an informed consent form and provided basic demographic information. Next, the respondents watched the first online digital nature video, which was embedded within the survey (via the video website Vimeo). Respondents were instructed to turn on their sound and watch the video full screen. After watching the video, a control question was implemented to ensure that respondents actually managed to play the video as instructed. Subsequently, respondents were asked to fill out the first post-exposure survey including the outcome measures. Subsequently, respondents watched the second video and filled out the second (post-exposure) survey. Respondents who watched both videos and completed the entire survey were rewarded with US $\$ 4$.

\section{Measures}

All survey responses were recorded using five-point Likert scales in survey software Qualtrics. For an extensive list of all items used, see Appendix 2.

Social aspirations. Social aspirations were measured with the Social Aspirations Scale (van Houwelingen-Snippe et al., 2020a), with five items tapping the appropriateness of the nature scene for social interaction as indicated by items such as 'I would like to show this landscape to someone' and 'This landscape is suitable to experience together' $(\alpha=0.80)$.

Awe. Awe was measured with the sub-constructs Connectedness, Self-diminishment and Vastness of the original Awe Experience Scale (Yaden 

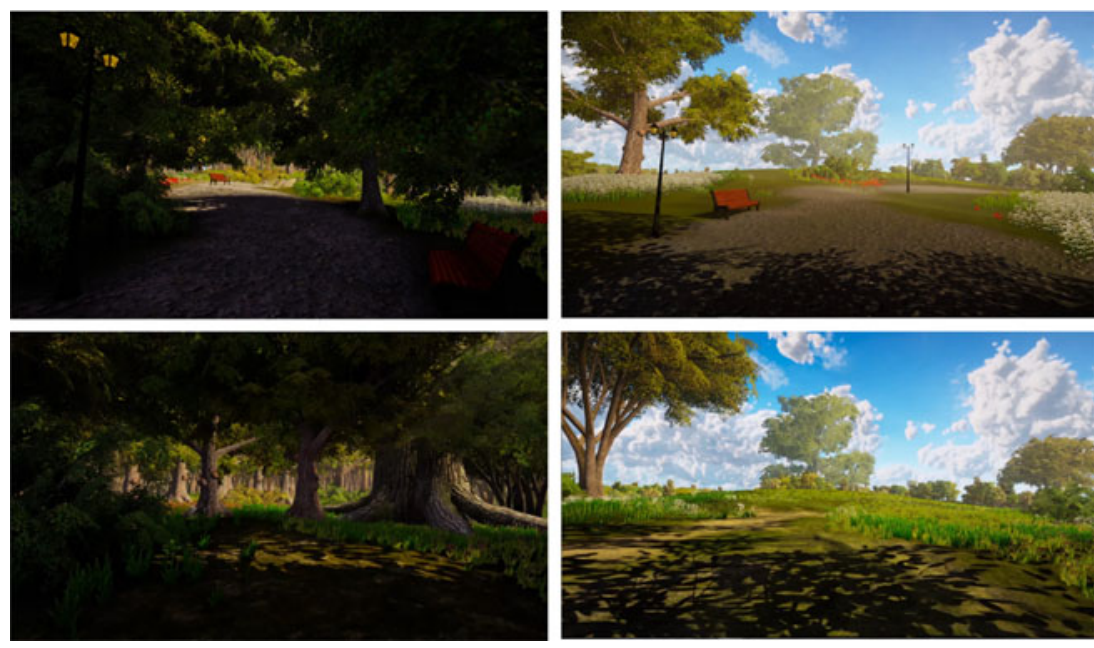

Figure 2. Screen shots of digital nature scenes used in the survey (top-left: dense tended nature; top-right: spacious tended nature; bottom-left: dense wild nature; bottom-right: spacious wild nature).

et al., 2018), and includes 14 items such as 'I felt small compared to everything else' and 'I experienced a sense of oneness with all things' $(\alpha=0.96)$.

Fascination. Fascination was measured with the Fascination construct of the original Perceived Restorativeness Scale (Hartig et al., 1997), including five items such as: 'The setting has fascinating qualities' and 'There is much to explore and discover here' $(\alpha=0.92)$.

Sense of presence. As immersion (e.g. sense of presence) is considered to be one of the main benefits of digital nature, we included sense of presence in the questionnaire for explorative purposes. Sense of presence was measured with the selflocation construct of the original Spatial Presence Experience Scale (Hartmann et al., 2016), and taps the extent to which one feels more or less present in the environment of the video, as indicated by eight items such as 'I felt like I was actually there in the environment of the video' and 'I had the feeling that I was in the middle of the action rather than merely observing' $(\alpha=0.96)$.

\section{Results}

Demographic profile

Basic demographic information of the respondents is presented in Table 1.

\section{Analyses of variances}

Mixed design analyses of variance tests were conducted with, respectively, social aspirations, awe, fascination and sense of presence as dependent variables, with spaciousness as within-subject factor and type of nature as between-subjects factor. 
Table 1. Demographic profile

\begin{tabular}{|c|c|c|}
\hline Category & Specification & $\begin{array}{l}\text { Number of } \\
\text { respondents }\end{array}$ \\
\hline \multirow[t]{4}{*}{ Year of birth } & Before 1950 & 31 \\
\hline & $1950-1954$ & 47 \\
\hline & 1955-1959 & 71 \\
\hline & After 1959 & 51 \\
\hline \multirow[t]{2}{*}{ Gender } & Male & 69 \\
\hline & Female & 131 \\
\hline \multirow[t]{3}{*}{ Country of residence } & United States of America & 196 \\
\hline & Canada & 2 \\
\hline & North-West Europe & 2 \\
\hline \multirow[t]{6}{*}{ Highest degree } & High school or less & 32 \\
\hline & $\begin{array}{l}\text { Some college but no } \\
\text { degree }\end{array}$ & 51 \\
\hline & Associate degree & 27 \\
\hline & Bachelor's degree & 56 \\
\hline & Master's degree & 24 \\
\hline & $\begin{array}{l}\text { Professional or doctoral } \\
\text { degree }\end{array}$ & 10 \\
\hline \multirow[t]{4}{*}{ Marital status } & Married & 84 \\
\hline & Never married & 36 \\
\hline & Divorced or separated & 61 \\
\hline & Widowed & 19 \\
\hline \multirow[t]{2}{*}{ Living area } & Rural & 68 \\
\hline & Urban & 132 \\
\hline \multirow{4}{*}{$\begin{array}{l}\text { Number of physical nature interactions } \\
\text { during a week }\end{array}$} & Less than once & 7 \\
\hline & $1-2$ times & 69 \\
\hline & $3-5$ times & 68 \\
\hline & More than 5 times & 56 \\
\hline
\end{tabular}

Social aspirations. The main effect of spaciousness was marginally significant ( $F$ $\left.(1,198)=3.2, p=0.08, \eta^{2}=0.02\right)$, suggesting higher social aspiration scores for spacious nature scenes $($ mean $=3.62$, standard deviation $(\mathrm{SD})=0.73$ ) compared to dense nature scenes (mean $=3.52, \mathrm{SD}=0.81$ ).

Moreover, the effect of nature type was significant $(F(1,198)=19.81, p<0.001$, $\eta^{2}=0.09$ ), indicating that tended nature scenes (mean $=3.77, \mathrm{SD}=0.63$ ) elicited more social aspirations than wild nature scenes (mean $=3.36, \mathrm{SD}=0.85)$.

The interaction between type of nature and spaciousness was not significant $\left(F(1,198)=2.22, p=0.14, \eta^{2}=0.01\right)$. 
Fascination. The effect of spaciousness on fascination scores was significant $\left(F(1,198)=7.32, p<0.01, \eta^{2}=0.04\right)$, showing that dense nature scenes (mean $=$ 3.90, $\mathrm{SD}=0.83$ ) elicited higher fascination scores compared to spacious nature scenes (mean $=3.70, \mathrm{SD}=0.88$ ).

Additionally, there was a significant effect of type of nature on fascination $\left(F(1,198)=4.22, p<0.05, \eta^{2}=0.02\right)$, indicating that tended nature scenes (mean $=3.90, \mathrm{SD}=0.80)$ elicited higher fascination scores compared to wild nature scenes $($ mean $=3.70, \mathrm{SD}=0.90)$.

Again, the interaction between type of nature and spaciousness was not significant $\left(F(1,198)=1.19, p=0.28, \eta^{2}=0.01\right)$.

Awe. There was no significant effect of spaciousness on awe scores $(F(1,198)=2.61, p$ $\left.=0.11, \eta^{2}=0.01\right)$. However, the effect of type of nature was significant $(F(1,198)=3.96$, $\left.p<0.05,=\eta^{2}=0.02\right)$ : tended nature scenes (mean $\left.=3.09, \mathrm{SD}=0.92\right)$ elicited higher awe scores compared to wild nature scenes (mean $=2.84, \mathrm{SD}=0.97$ ). The interaction between nature type and spaciousness was not significant $(F<1$, not significant).

Sense of presence. The main effect of spaciousness on sense of presence score was significant $\left(F(1,198)=5.38, p<0.05, \eta^{2}=0.03\right)$, indicating that dense nature scenes (mean $=3.11, \mathrm{SD}=1.09$ ) elicited a higher sense of presence scores than spacious nature scenes $($ mean $=3.0, \mathrm{SD}=1.04)$.

The main effect of type of nature was also significant $(F(1,198)=5.96, p=0.02$, $\left.\eta^{2}=0.03\right)$, indicating that tended nature scenes (mean $\left.=3.21, \mathrm{SD}=1.05\right)$ elicited a higher sense of presence compared to wild nature scenes (mean $=2.87, \mathrm{SD}=1.05$ ).

Finally, the interaction between nature type and spaciousness was not significant $\left(F(1,198)=1.28, p=0.26, \eta^{2}=0.01\right)$.

\section{Summary Study 2}

The aim of Study 2 was to test the effects of the enhanced digital nature scenes (varying in terms of spaciousness and type of nature) on measures related to social wellbeing, including social aspirations, awe, fascination and sense of presence (Aim 2). Results clearly demonstrate the potential of tended (rather than wild) nature for enhancing measures related to social wellbeing. That is, tended nature scenes elicited significantly more social aspirations and positive emotions (fascination and awe), and were more effective in triggering a sense of presence. Effects of spaciousness on social aspirations were marginally significant, suggesting that spacious settings may enhance prosocial aspirations, but in line with the focus group sessions, effects of nature type were much more pronounced. Finally, dense (rather than spacious) nature was considered more fascinating.

\section{General discussion}

The findings presented across the two studies underscore the potential of digital nature for enhancing social aspirations and positive emotions. To our knowledge, this is one of the first studies to (a) pinpoint specific nature characteristics important to social wellbeing and (b) systematically vary nature characteristics using VR 
software. Although the potential of VR technology for immersing people in natural settings has been demonstrated previously (e.g. Chirico and Gaggioli, 2019), previous research used footage of existing nature settings. Clearly, a major benefit of designing nature settings from scratch is that full control over (systematic) variations between nature scenes is possible.

In sum, our findings indicate that immersive technologies hold great promise for reintroducing nature into the lives of people for whom access to nature is difficult or impossible. Furthermore, findings from the focus groups suggest that acceptance and attitude towards digital nature is particularly high for older adults with mobility restrictions and related perceptions of reduced autonomy and independence, which are important determinants of wellbeing (Gabriel and Bowling, 2004). Hence, especially for these people, digital nature can be considered an essential complementary means for interacting with nature. However, when considering the current COVID-19 pandemic and the recent lockdowns, the potential of digital nature is by no means limited to older adults only, as also evidenced by a recent study assessing the effects of digital nature during the worldwide lockdowns (van Houwelingen-Snippe et al., 2020b).

When turning to the results of both the focus group sessions and the quantitative survey, our findings indicate that for older adults, tended nature settings are generally preferred over wild nature. In a previous laboratory study among international university students (van Houwelingen-Snippe et al., 2020a), no such effects of type of nature were found. Arguably, the importance of tended nature (associated with higher levels of comfort and safety) is much more pronounced for older adults, which is not only in line with the findings from the focus group sessions (Study 1) but also with previous research (e.g. Wen et al., 2018).

The effects of nature type on awe and fascination (showing that tended nature positively influences these affective states) in particular contrast with previous nature studies, rather demonstrating positive effects of wild and more mysterious nature settings (Kaplan and Kaplan, 1989; Szolosi et al., 2014; van Rompay and Jol, 2016; Chiang et al., 2017). Again, these findings might relate to target group characteristics with older (rather than young) adults arguably feeling more at ease and hence more open to experiencing awe and fascination in tended, rather than wild, scenes. Clearly, these findings call for follow-up research in which the role of safety and comfort perceptions as a function of nature type and mobility restrictions is tested.

The main effects of spaciousness on fascination and sense of presence (showing that dense scenes were rated as more fascinating and created a stronger sense of presence compared to spacious scenes) are in line with previous research (Chiang et al., 2017). However, the effect of spaciousness on social aspirations (showing that spacious landscapes elicited more social aspirations) was only marginally significant, whereas in previous research, the effect of spaciousness on social aspirations was particularly pronounced among young adults (van Houwelingen-Snippe et al., 2020a). Arguably, the denser (less-spacious) settings trigger a greater sense of intimacy and privacy as they shield one off from the environment and other people present.

Another factor that might explain the difference in effects of spaciousness on social aspirations between the present study and previous research relates to 
presentation mode. Whereas in previous research, the digital nature scenes were presented on a large and immersive projection wall (van Houwelingen-Snippe et al., 2020a), the digital nature scenes in the present study were presented as videos merged into an online survey which participants watched on their own device at home. When also considering the finding that sense of presence was significantly higher in the dense (rather than the spacious) condition, arguably the spaciousness manipulation (and the sense of vastness it aimed to trigger) did not come across as convincingly on a small screen. When enhancing interactivity in future iterations of the digital nature scenes, e.g. by providing ways to move around in the digital nature environment, sense of presence and immersion might be boosted likewise.

\section{Limitations and future research}

Although participants of both studies were residing in Western countries, namely the Netherlands and the USA, the two studies described in this article did not use a similar sample of participants. The participants of the focus groups were exclusively Dutch care centre residents or care receivers, whereas the respondents of the online survey study were generally younger and mostly residing in the USA. Future research should point out whether the findings of the online survey are generalisable to a population for whom loneliness and mobility restrictions are particularly pressing issues. Such studies should also provide insight into how demographics, presence of nearby nature and social context (i.e. watching alone or watching with others) shape preferences for different nature scenes. For instance, recent findings indicate that having nature nearby is positively correlated with feelings of connectedness (Cartwright et al., 2018; van Houwelingen-Snippe et al., 2020b), further stressing the importance of introducing digital nature into people's living environments.

Although our findings clearly point at the potential of digital nature for enhancing social aspirations and positive emotions, follow-up research should investigate the effects of digital nature on measures requiring longitudinal research, such as loneliness, quality of life and life satisfaction. Furthermore, previous research showed that people living close to nature experience less feelings of loneliness (Maas et al., 2009). These findings warrant studies exploring the relationship between digital nature and loneliness.

Furthermore, the stationary scenes used in this study did not capitalise fully on the potential of VR technology which also allows for more autonomy and interaction (e.g. being able to walk and being in control of factors such as walking direction and speed of movement) and the depiction of social presence (i.e. cues signalling the presence of others such as silhouettes or avatars or the sound of children playing). Considering the focus on social wellbeing, such additions could increase the potential of digital nature further.

When designing digital nature interactions for older adults, the findings of Study 1 seem to suggest that older adults who perceive a lack of nature interactions might benefit most from doses of (digital) nature interactions incorporated into daily activities. On the other hand, users who experience nature more frequently might be drawn to more adventurous technology and/or scenes that add something more exciting or adventurous to what one is exposed to during the day. Since personal needs and preferences vary greatly among the heterogeneous user group, 
researchers should not aim for a one-size-fits-all product, but rather aim for a person-centred approach (Hendriks et al., 2016). Future research should point out how to personalise digital nature scenes based on needs and expectations.

Finally, future studies could explore further the role of being active (versus passive) in nature. Considering that for many, being in nature is usually associated with engagement in a variety of activities (e.g. exercising, gardening, meeting others), whereas for others being in nature might be foremost associated with a more passive mode of experience (e.g. enjoying the view while sitting on a bench), it might be particularly worthwhile to test how more active or passive uses of nature influence social wellbeing measures. Although research findings generally testify to more positive effects for a more active mode of experience (Holt et al., 2019; Rogerson et al., 2020; Unruh et al., 2000), it is an open question to what extent this also applies to engagement in digital nature environments where activity might relate to, for instance, active exploration of a digital nature environment using controllers or related means. Clearly, in such cases, digital skills important for navigating virtual environments should be considered as well (Xie, 2003).

\section{Conclusion}

This research shows that digital nature can elicit social aspirations and enhance social wellbeing among older adults. These findings contribute to the very small base of existing research on effects of wellbeing by pinpointing design considerations for digital nature environments and by indicating how preferences vary with mobility restrictions. Furthermore, our findings shed light on essential nature characteristics and warrant further research and development of digital nature applications for inspiring social connectedness, reducing loneliness and enhancing overall wellbeing.

Financial support. This work was supported by ZonMW (CreateHealth grant number 443001106).

Conflict of interest. The authors declare no conflict of interest.

Ethical standards. Studies were approved by the ethical committee of the University of Twente (request numbers 191301 and 200541).

\section{Notes}

1 See https://assetstore.unity.com/packages/tools/terrain/gaia-terrainscene-generator-42618.

2 Participants are referred to by their group number followed by their participant number ('1.1' refers to group 1, participant 1). For a demographic profile of the participants, see Appendix 1.

3 See https://assetstore.unity.com/packages/tools/terrain/gaia-terrainscene-generator-42618.

\section{References}

Battisto D, Vincent E and Dye CJ (2018) Technological supports to increase nature contact for older adults. In Pak R and Mclaughlin A (eds), Aging, Technology and Health. Academic Press, pp. 113-133.

Bergefurt L, Kemperman A, van den Berg P, Borgers A, van der Waerden P, Oosterhuis G and Hommel M (2019) Loneliness and life satisfaction explained by public-space use and mobility patterns. International Journal of Environmental Research and Public Health 16, 4282.

Beukeboom CJ, Langeveld D and Tanja-Dijkstra K (2012) Stress-reducing effects of real and artificial nature in a hospital waiting room. Journal of Alternative and Complementary Medicine 18, 329-333. 
Bratman GN, Anderson CB, Berman MG, Cochran B, de Vries S, Flanders J, Folke C, Frumkin H, Gross JJ, Hartig T, Kahn PH, Kuo M, Lawler JJ, Levin PS, Lindahl T, Meyer-Lindenberg A, Mitchell R, Ouyang Z, Roe J, Scarlett L, Smith JR, van den Bosch M, Wheeler BW, White MP, Zheng H and Daily GC (2019) Nature and mental health: an ecosystem service perspective. Science Advances 5, eaax0903.

Browning MHEM, Mimnaugh KJ, van Riper CJ, Laurent HK and LaValle SM (2020) Can simulated nature support mental health? Comparing short, single-doses of 360-degree nature videos in virtual reality with the outdoors. Frontiers in Psychology 10, 2667.

Bruun-Pedersen JR, Pedersen KS, Serafin S and Kofoed LB (2014) Augmented exercise biking with virtual environments for elderly users: a preliminary study for retirement home physical therapy. In 2014 2nd Workshop on Virtual and Augmented Assistive Technology (VAAT). Minneapolis, MN, USA: IEEE, pp. 23-27.

Bruun-Pedersen JR, Serafin S and Kofoed LB (2016) Going outside while staying inside - exercise motivation with immersive vs. non-immersive recreational virtual environment augmentation for older adult nursing home residents. In Proceedings - 2016 IEEE International Conference on Healthcare Informatics, ICHI 2016. Chicago, IL, USA: IEEE, pp. 216-226.

Buecker S, Ebert T, Götz FM, Entringer TM and Luhmann M (2020) In a lonely place: investigating regional differences in loneliness. Social Psychological and Personality Science 12, 147-155.

Cacioppo JT, Chen HY and Cacioppo S (2017) Reciprocal influences between loneliness and selfcenteredness: a cross-lagged panel analysis in a population-based sample of African American, Hispanic, and Caucasian adults. Personality and Social Psychology Bulletin 43, 1125-1135.

Cartwright BDS, White MP and Clitherow TJ (2018) Nearby nature 'buffers' the effect of low social connectedness on adult subjective wellbeing over the last 7 days. International Journal of Environmental Research and Public Health 15, 1238.

Chiang YC, Li D and Jane HA (2017) Wild or tended nature? The effects of landscape location and vegetation density on physiological and psychological responses. Landscape and Urban Planning 167, 72-83.

Chirico A and Gaggioli A (2019) When virtual feels real: comparing emotional responses and presence in virtual and natural environments. Cyberpsychology, Behavior, and Social Networking 22, 220-226.

Choe EY, Jorgensen A and Sheffield D (2020) Simulated natural environments bolster the effectiveness of a mindfulness programme: a comparison with a relaxation-based intervention. Journal of Environmental Psychology 67, 101382.

Cohen AB, Gruber J and Keltner D (2010) Comparing spiritual transformations and experiences of profound beauty. Psychology of Religion and Spirituality 2, 127.

Corbin J and Strauss A (1990) Grounded theory research: procedures, canons and evaluative criteria. Zeitschrift für Sociologie 19, 418-427.

Courtin E and Knapp M (2017) Social isolation, loneliness and health in old age: a scoping review. Health and Social Care in the Community 25, 799-812.

de Bruin SR, Buist Y, Hassink J and Vaandrager L (2021) 'I want to make myself useful': the value of nature-based adult day services in urban areas for people with dementia and their family carers. Ageing \& Society 41, 582-604.

de Koning JL, Stathi A and Richards S (2017) Predictors of loneliness and different types of social isolation of rural-living older adults in the United Kingdom. Ageing \& Society 37, 2012-2043.

Detweiler MB, Sharma T, Detweiler JG, Murphy PF, Lane S, Carman J, Chudhary AS, Halling MH and Kim KY (2012) What is the evidence to support the use of therapeutic gardens for the elderly? Psychiatry Investigation 9, 100-110.

Dickens AP, Richards SH, Greaves CJ and Campbell JL (2011) Interventions targeting social isolation in older people: a systematic review. BMC Public Health 11, 647.

Fakoya OA, McCorry NK and Donnelly M (2020) Loneliness and social isolation interventions for older adults: a scoping review of reviews. BMC Public Health 20, 129.

Finlay J, Franke T, McKay H and Sims-Gould J (2015) Therapeutic landscapes and wellbeing in later life: impacts of blue and green spaces for older adults. Health and Place 34, 97-106.

Gabriel Z and Bowling A (2004) Quality of life from the perspectives of older people. Ageing \& Society 24, 675-691.

Hartig T, Korpela K, Evans GW and Gärling T (1997) A measure of restorative quality in environments. Scandinavian Housing \& Planning Research 175-194. 
Hartmann T, Wirth W, Schramm H, Klimmt C, Vorderer P, Gysbers A, Böcking S, Ravaja N, Laarni J, Saari T, Gouveia F and Sacau AM (2016) The spatial presence experience scale (SPES): a short selfreport measure for diverse media settings. Journal of Media Psychology 28, 1-15.

Hawkley LC and Cacioppo JT (2007) Aging and loneliness: downhill quickly? Current Directions in Psychological Science 16, 187-191.

Hendriks IH, Van Vliet D, Gerritsen DL and Dröes RM (2016) Nature and dementia: development of a person-centered approach. International Psychogeriatrics 28, 1455-1470.

Hernandez RO (2007) Effects of therapeutic gardens in special care units for people with dementia. Journal of Housing for the Elderly 21, 153-177.

Holt EW, Lombard QK, Best N, Smiley-Smith S and Quinn JE (2019) Active and passive use of green space, health, and well-being amongst university students. International journal of environmental research and public health $\mathbf{1 6}, 424$.

Joye Y and Bolderdijk JW (2014) An exploratory study into the effects of extraordinary nature on emotions, mood, and prosociality. Frontiers in Psychology 5, 1577.

Kabisch N, van den Bosch M and Lafortezza R (2017) The health benefits of nature-based solutions to urbanization challenges for children and the elderly-a systematic review. Environmental Research 159, 362-373.

Kaplan R and Kaplan S (1989) The Experience of Nature: A Psychological Perspective. Cambridge: Cambridge University Press.

Keltner D and Haidt J (2003) Approaching awe, a moral, spiritual, and aesthetic emotion. Cognition and Emotion 17, 297-314.

Keniger LE, Gaston KJ, Irvine KN and Fuller RA (2013) What are the benefits of interacting with nature? International Journal of Environmental Research and Public Health 10, 913-935.

Landeiro F, Barrows P, Nuttall Musson E, Gray AM and Leal J (2017) Reducing social isolation and loneliness in older people: a systematic review protocol. BMJ Open 7, e013778.

Lin YH, Tsai CC, Sullivan WC, Chang PJ and Chang CY (2014) Does awareness effect the restorative function and perception of street trees?. Frontiers in psychology 5, 906.

Liu BS and Rook KS (2013) Emotional and social loneliness in later life: associations with positive versus negative social exchanges. Journal of Social and Personal Relationships 30, 813-832.

Ludden GDS, van Rompay TJL, Niedderer K and Tournier I (2019) Environmental design for dementia care - towards more meaningful experiences through design. Maturitas 128, 10-16.

Maas J, van Dillen SME, Verheij RA and Groenewegen PP (2009) Social contacts as a possible mechanism behind the relation between green space and health. Health and Place 15, 586-595.

Milligan C, Gatrell A and Bingley A (2004) 'Cultivating health': therapeutic landscapes and older people in northern England. Social Science \& Medicine 58, 1781-1793.

Murphy PF, Miyazaki Y, Detweiler MB and Kim KY (2010) Longitudinal analysis of differential effects on agitation of a therapeutic wander garden for dementia patients based on ambulation ability. Dementia 9 , 355-373.

Mutafoglu K, Ten Brink P, Schweitzer J, Jonesh H and Blake R (2017) Nature for Health and Equity. Brussels: Institute for European Environmental Policy. Available at https://ieep.eu/publications/2017/ 03/access-to-nature-reduces-health-inequalities-an-ieep-briefing.

Piff PK, Dietze P, Feinberg M, Stancato DM and Keltner D (2015) Awe, the small self, and prosocial behavior. Journal of Personality and Social Psychology 108, 883-899.

Rogerson M, Colbeck I, Bragg R, Dosumu A and Griffin M (2020) Affective outcomes of group versus lone green exercise participation. International journal of environmental research and public health $\mathbf{1 7}$, 624.

Ryan GW and Bernard HR (2003) Techniques to identify themes. Field methods 15, 85-109.

Shiota MN, Keltner D and Mossman A (2007) The nature of awe: Elicitors, appraisals, and effects on selfconcept. Cognition and emotion 21, 944-963.

Smith KJ and Victor C (2019) Typologies of loneliness, living alone and social isolation, and their associations with physical and mental health. Ageing \& Society 39, 1709-1730.

Sorkin D, Rook KS and Lu JL (2002) Loneliness, lack of emotional support, lack of companionship, and the likelihood of having a heart condition in an elderly sample. Annals of Behavioral Medicine 24, 290-298. 
Staats H and Hartig T (2004) Alone or with a friend: a social context for psychological restoration and environmental preferences. Journal of Environmental Psychology 24, 199-211.

Szolosi AM, Watson JM and Ruddell EJ (2014) The benefits of mystery in nature on attention: assessing the impacts of presentation duration. Frontiers in psychology 5, 1360.

ten Bruggencate T, Luijkx KG and Sturm J (2019) When your world gets smaller: how older people try to meet their social needs, including the role of social technology. Ageing \& Society 39, 1826-1852.

Ulrich RS (1984) View through a window may influence recovery from surgery. Science 224, 420-421.

Unruh AM, Smith N and Scammell C (2000) The occupation of gardening in life-threatening illness: A qualitative pilot project. Canadian Journal of Occupational Therapy 67, 70-77.

van Houwelingen-Snippe J, van Rompay TJL, de Jong MDT and Ben Allouch S (2020a) Does digital nature enhance social aspirations? An experimental study. International Journal of Environmental Research and Public Health 17, 1454.

Van Houwelingen-Snippe J, Van Rompay TJ and Ben Allouch S (2020b) Feeling connected after experiencing digital nature: A survey study. International journal of environmental research and public health 17, 6879.

van Rompay TJL and Jol T (2016) Wild and free: unpredictability and spaciousness as predictors of creative performance. Journal of Environmental Psychology 48, 140-148.

Weinstein N, Przybylski AK and Ryan RM (2009) Can nature make us more caring? Effects of immersion in nature on intrinsic aspirations and generosity. Personality and Social Psychology Bulletin 35, 1315-1329.

Wen C, Albert C and Von Haaren C (2018) The elderly in green spaces: exploring requirements and preferences concerning nature-based recreation. Sustainable Cities and Society 38, 582-593.

White MP, Yeo NL, Vassiljev P, Lundstedt R, Wallergård M, Albin M and Lõhmus M (2018) A prescription for 'nature' - the potential of using virtual nature in therapeutics. Neuropsychiatric Disease and Treatment 14, 3001-3013.

Wood L, Hooper P, Foster S and Bull F (2017) Public green spaces and positive mental health - investigating the relationship between access, quantity and types of parks and mental wellbeing. Health and Place 48, 63-71.

Xie B (2003) Older adults, computers, and the Internet: Future directions. Gerontechnology 2, 289-305.

Yaden DB, Kaufman SB, Hyde E, Chirico A, Gaggioli A, Zhang JW and Keltner D (2018) The development of the Awe Experience Scale (AWE-S): a multifactorial measure for a complex emotion. Journal of Positive Psychology 1-15.

Zelenski JM and Nisbet EK (2014) Happiness and feeling connected: the distinct role of nature relatedness. Environment and Behavior 46, 3-23.

\section{Appendix 1: Focus group participants}

\begin{tabular}{|lcccc}
\hline Participant $^{1}$ & Gender & Age & Living situation $^{2}$ & In (electronic) wheelchair \\
\hline 1.1 & Female & 86 & Internally & Yes \\
\hline 1.2 & Female & 91 & Internally & Yes \\
\hline 1.3 & Female & Unknown & Internally & No \\
\hline 1.4 & Female & 78 & Internally & Yes \\
\hline 1.5 & Male & 72 & Internally & Yes \\
\hline 2.1 & Female & 91 & Externally & No \\
\hline 2.2 & Female & 83 & Externally & No \\
\hline 2.3 & Female & 91 & Externally & No \\
\hline
\end{tabular}

(Continued) 
(Continued.)

\begin{tabular}{|c|c|c|c|c|}
\hline Participant $^{1}$ & Gender & Age & Living situation $^{2}$ & In (electronic) wheelchair \\
\hline 2.4 & Female & 88 & Externally & No \\
\hline 2.5 & Female & 90 & Externally & No \\
\hline 2.6 & Female & 81 & Externally & No \\
\hline 2.7 & Female & 90 & Externally & No \\
\hline 2.8 & Female & 92 & Internally & Yes \\
\hline 2.9 & Male & 88 & Internally & No \\
\hline 3.1 & Female & 86 & Internally & No \\
\hline 3.2 & Female & 92 & Internally & Yes \\
\hline 3.3 & Female & 73 & Externally & No \\
\hline 3.4 & Female & 86 & Internally & No \\
\hline 4.1 & Male & 78 & Internally & Yes \\
\hline 4.2 & Male & 75 & Internally & No \\
\hline 4.3 & Female & 73 & Internally & Yes \\
\hline 4.4 & Male & 88 & Internally & No \\
\hline 5.1 & Female & 82 & Externally & Yes \\
\hline 5.2 & Female & 85 & Externally & No \\
\hline 5.3 & Female & 69 & Externally & Yes \\
\hline 5.4 & Male & 76 & Externally & No \\
\hline
\end{tabular}

Notes: 1. Participants are referred to by their group number followed by their participant number ('1.1' refers to group 1 , participant 1). 2. Living internally means living within a care centre. In the Netherlands, most older adults are forced to live independently for as long as possible, so only people with severe care needs are given the chance to live within care centres. Living externally means living independently with (informal) care at home. All participants were invited to participate in the focus groups by the care centres, so these participants received some kind of care provided by the care centre.

\section{Appendix 2: Measures Study 2}

\section{Social Aspirations Scale}

van Houwelingen-Snippe et al. (2020a), $\alpha=0.80$

(1) I would like to show this landscape to someone.

(2) I would like to meet here with a friend.

(3) I would like to make a spontaneous chat.

(4) This landscape is suitable to experience together.

(5) If I would encounter someone here, I would feel uncomfortable (Reverse).

\section{Perceived Restorativeness Scale}

Hartig et al. (1997), $\alpha=0.92$

(1) The setting has fascinating qualities.

(2) My attention is drawn to many interesting things. 
(3) I would like to get to know this place better.

(4) There is much to explore and discover here.

(5) I would like to spend more time looking at the surroundings.

\section{Awe Experience Scale}

Yaden et al. (2018), $\alpha=0.96$

(1) I felt that my sense of self was diminished.

(2) I experienced a reduced sense of self.

(3) I felt my sense of self become somehow smaller.

(4) I felt small compared to everything else.

(5) I had the sense of being connected to everything.

(6) I felt a sense of communion with all living things.

(7) I experienced a sense of oneness with all things.

(8) I felt closely connected to humanity.

(9) I had a sense of complete connectedness.

(10) I felt that I was in the presence of something grand.

(11) I experienced something greater than myself.

(12) I felt in the presence of greatness.

(13) I perceived something that was much larger than me.

(14) I perceived vastness.

\section{Spatial Presence Experience Scale}

Hartmann et al. (2016), $\alpha=0.96$

(1) I felt like I was actually there in the environment of the video.

(2) It was as though my true location had shifted into the environment in the video.

(3) I felt as though I was physically present in the environment of the video.

(4) I experienced the environment of the video as though I had stepped into a different place.

(5) I was convinced that things were actually happening around me.

(6) I had the feeling that I was in the middle of the action rather than merely observing.

(7) I felt like the objects in the video surrounded me.

(8) I was convinced that the objects in the video were located on the various sides of my body.

Cite this article: van Houwelingen-Snippe J, Ben Allouch S, van Rompay TJL (2022). 'That is a place where I would want to go': investigating digital nature to enhance social wellbeing among older adults. Ageing \& Society $1-24$. https://doi.org/10.1017/S0144686X2100177X 